\title{
Effect of $\delta$ Phase on Microstructure and Hardness of Heat-Affected Zone in TIG-Welded GH4169 Superalloy
}

\author{
Tian-Fu Wang ${ }^{1,2} \cdot$ Xin-Jie $\mathrm{Di}^{1,2} \cdot$ Cheng-Ning $\mathrm{Li}^{1,2} \cdot$ Jia-Mei Wang ${ }^{1,2} \cdot$ Dong-Po Wang ${ }^{1,2}$
}

Received: 7 September 2018 / Revised: 22 October 2018 / Published online: 11 December 2018

(c) The Chinese Society for Metals (CSM) and Springer-Verlag GmbH Germany, part of Springer Nature 2018

\begin{abstract}
The GH4169 superalloy with different content of $\delta-\mathrm{Ni}_{3} \mathrm{Nb}$ phase was welded by tungsten inert gas welding. A detailed study of microstructure and hardness of heat-affected zone (HAZ) was performed in both as-welded and aged state. The results show that the precipitation of $\delta$ phase, especially the intergranular $\delta$ phase, can lead to the enrichment of $\mathrm{Nb}$ and Mo elements, which promote the formation of $\gamma /$ Laves eutectic constituent at grain boundaries in HAZ. In as-welded state, the hardness decreases first and then increases (exhibiting a "V" shape) with distance away from fusion line in HAZ, which is governed by grain size. After aging treatment, however, the $\gamma$ " phase plays a key role in hardness and leads to the " $\Lambda$ " shape profiles of hardness in HAZ.
\end{abstract}

Keywords GH4169 superalloy $\cdot$ TIG (tungsten inert gas) welding $\cdot \delta$ phase $\cdot \gamma^{\prime \prime}$ phase $\cdot$ Element enrichment

\section{Introduction}

As a precipitation-strengthened nickel-based superalloy, GH4169 (according to Chinese classification [1], similar to Inconel 718) has excellent mechanical strength at a temperature range from -253 to $700{ }^{\circ} \mathrm{C}$. It is widely used in aerospace, petrochemical and energy industries. The main strengthening phase of this alloy is body-centered tetragonal $\gamma^{\prime \prime}\left(\mathrm{Ni}_{3} \mathrm{Nb}\right)$ phase. However, the $\gamma^{\prime \prime}$ phase will transform into the more stable orthorhombic $\delta\left(\mathrm{Ni}_{3} \mathrm{Nb}\right)$ phase during the high-temperature service [2,3], which is incoherent with the $\gamma$ matrix [4]. After long-term high-temperature service, a large content of needle-like $\delta$ phase with different orientations will be accumulated in GH4169 superalloy. When the needle-like $\delta$ phase is oriented perpendicular to the service load, it will promote the nucleation and propagation of fatigue cracks [5]. To extend the service life of high-temperature component, these cracks are often repaired by low heat

Available online at http://link.springer.com/journal/40195

Xin-Jie Di

dixinjie@tju.edu.cn

1 School of Materials Science and Engineering, Tianjin University, Tianjin 300350, China

2 Tianjin Key Laboratory of Advanced Joining Technology, Tianjin 300350, China input techniques, such as tungsten inert gas (TIG) welding and laser beam welding [6].

Research shows that the initial microstructure, especially the $\delta$ phase, has a great impact on microstructure transformation in GH4169 superalloy during high-temperature solution treatment [7]. Nalawade et al. [8] found that the precipitation of $\delta$ phase can change the $\mathrm{Nb} /(\mathrm{Al}+\mathrm{Ti})$ ratio, which influence the precipitation of $\gamma^{\prime \prime}$ phase. By research the hot ductility of Alloy 718, Andersson et al. [9] proposed that the $\mathrm{NbC}$ assisted by $\delta$ phase can promote the formation of liquation phase and deteriorate the ductility. Hooijmans et al. [10] investigated the liquation cracking susceptibility of Inconel 718 and found that the dissolution of $\delta$ phase in heat-affected zone (HAZ) during welding can promote the formation of low melting films at the grain boundaries. Qian and Lippold [11] proposed the eliminating $\delta$ phase through rejuvenation heat treatment can slightly improve the quality of HAZ. Some other researchers also found that as long as the $\delta$ phase is not completely dissolved, it can restrain grain growth through its pinning effect on grain boundaries [12, 13].

Therefore, the effects of $\delta$ phase on microstructure transformation during welding are closely related to its dissolution process, which is controlled by the weld thermal cycle and diffusion process of $\mathrm{Nb}$ atoms in $\gamma$ matrix [14]. During welding, there is a temperature gradient in HAZ, so the $\delta$ phase will be dissolved in different degrees. This means that the $\delta$ phase 
may have different effects on the microstructure transformation in different regions of HAZ. Therefore, in this research, efforts have been put out to investigate the microstructure transformation and hardness of HAZ in welded GH4169 superalloy. To simulate the microstructure of the long-term high-temperature serviced material, which contains large content of $\delta$ phase, heat treatment was performed before welding. Furthermore, the effect of $\delta$ phase on the microstructure transformation and hardness distribution of HAZ in both as-welded and aged state was discussed in detail.

\section{Materials and Methods}

The chemical composition of the used GH4169 superalloy in this study is given in Table 1. The as-received superalloy was in solid solution state. Before welding, the as-received GH4169 superalloy sheet was machined into $130 \mathrm{~mm} \times 100 \mathrm{~mm} \times 3.0 \mathrm{~mm}$ and then heat treated at $925^{\circ} \mathrm{C}$ for $1 \mathrm{~h}, 3 \mathrm{~h}$ and $9 \mathrm{~h}$, respectively, to obtain different content of $\delta$ phase. Subsequently, the samples of these four states (asreceived, $925^{\circ} \mathrm{C}$ for $1 \mathrm{~h}, 925^{\circ} \mathrm{C}$ for $3 \mathrm{~h}$ and $925^{\circ} \mathrm{C}$ for $9 \mathrm{~h}$ ) were welded by autogenous TIG welding. For the convenience of discussion, these four welded samples were named as S0, S1, S3 and S9, respectively, as shown in Fig. 1. The details of heat treatment and welding parameters are given in Table 2. After welding, the samples were aging treated: first, the samples were heat treated at $720^{\circ} \mathrm{C}$ for $8 \mathrm{~h}$ and then cooled to $620{ }^{\circ} \mathrm{C}$ in furnace. Next, the samples were held at $620{ }^{\circ} \mathrm{C}$ for $8 \mathrm{~h}$ and finally cooled to room temperature in air.

The content of $\delta$ phase of the samples was quantitatively measured by X-ray diffraction (XRD) with $\mathrm{Cu} K \alpha$ radiation. Metallographic samples were polished and etched $(5 \mathrm{~g}$ $\left.\mathrm{CuCl}_{2}+100 \mathrm{ml} \mathrm{HCl}+100 \mathrm{ml} \mathrm{C}_{2} \mathrm{H}_{5} \mathrm{OH}\right)$ and then examined by using an optical microscope (OM) and a scanning electron microscope (SEM) equipped with energy dispersive spectrometry (EDS) system. The chemical composition of precipitates was analyzed by EDS. The grain size distribution of HAZ was calculated by the processing software Image-Pro using magnified 1000× SEM images. The hardness test was performed according to the AWS D3.6-2010A standers using Vickers hardness tester with a load of $1.0 \mathrm{~kg}$ and a dwell time of $15 \mathrm{~s}$.

\section{Results}

\subsection{Microstructure After Heat Treatment of GH4169 Superalloy}

Figure 2 shows the SEM micrographs of GH4169 superalloy samples in different conditions. As shown in Fig. 2a, only a small amount of granular $\delta$ phase can be observed at the grain boundaries in as-received state sample. After heat treatment at $925^{\circ} \mathrm{C}$ for $1 \mathrm{~h}$, the size of granular $\delta$ phase is increased, and simultaneously a small amount of rod-like $\delta$ phase precipitates at grain boundaries (Fig. 2b). With the prolongation of the holding time at $925{ }^{\circ} \mathrm{C}$, some intragranular needle-like $\delta$ phase precipitates, and the size of intergranular $\delta$ phase is gradually increased (Fig. 2c). When the holding time increases to $9 \mathrm{~h}$, there are a large amount of coarsening intra- and intergranular $\delta$ phase in this alloy (Fig. 2d). The interesting result of the $\delta$ phase tended to first precipitate at grain boundaries, which can be ascribed to the following facts. One is that the nucleation barrier of intergranular $\delta$ phase is lower than that of intragranular $\delta$ phase, and the other possibility is the elemental segregation at the grain boundaries [15]. The grain size of the heat treated samples does not obviously increase compared to the as-received sample, which is mainly attributed to the pinning effect of the $\delta$ phase. The previous study about similar alloy has reported that the grain size does not grow when the temperature is lower than $980{ }^{\circ} \mathrm{C}$, but the grain coarsening occurs due to the complete dissolution of $\delta$ phase at higher temperature $[16,17]$.

Figure 3a shows the XRD patterns of samples for $2 \theta$ between $38^{\circ}$ and $50^{\circ}$, where the main diffraction peaks of $\delta$ phase and $\gamma$ matrix are included [2]. It involves diffraction peaks of $\delta$ phase from the crystal faces of (002), (201), (020), (012) and (211) and matrix from the crystal faces of (111) in this range. The most intense peak of $\gamma$ matrix and $\delta$ phase are detected in this range located at $43.53^{\circ}$ and $46.11^{\circ}$, respectively. Due to the tiny content of $\delta$ phase in as-received material, the characteristic diffraction peaks of $\delta$ phase cannot be detected. With the increase in holding time at $925^{\circ} \mathrm{C}$, the intensity of characteristic diffraction peaks of $\delta$ phase enhances, which indicates the increase in fraction of $\delta$ phase. The content of $\delta$ phase was determined by

Table 1 Chemical composition of the experimental GH4169 superalloy (wt\%)

\begin{tabular}{llllllll}
\hline $\mathrm{Ni}$ & $\mathrm{Cr}$ & $\mathrm{Nb}+\mathrm{Ta}$ & $\mathrm{Mo}$ & $\mathrm{Ti}$ & $\mathrm{Al}$ & $\mathrm{Si}$ & $\mathrm{C}$ \\
\hline 52.68 & 18.81 & 5.34 & 3.04 & 1.05 & 0.49 & 0.08 & 0.03 \\
\hline $\mathrm{Mn}$ & $\mathrm{S}$ & $\mathrm{P}$ & $\mathrm{Cu}$ & $\mathrm{Co}$ & $\mathrm{B}$ & $\mathrm{Ta}$ & $\mathrm{Fe}$ \\
\hline 0.03 & 0.001 & 0.008 & 0.01 & 0.01 & 0.003 & $<0.01$ & $\mathrm{Bal}$. \\
\hline
\end{tabular}




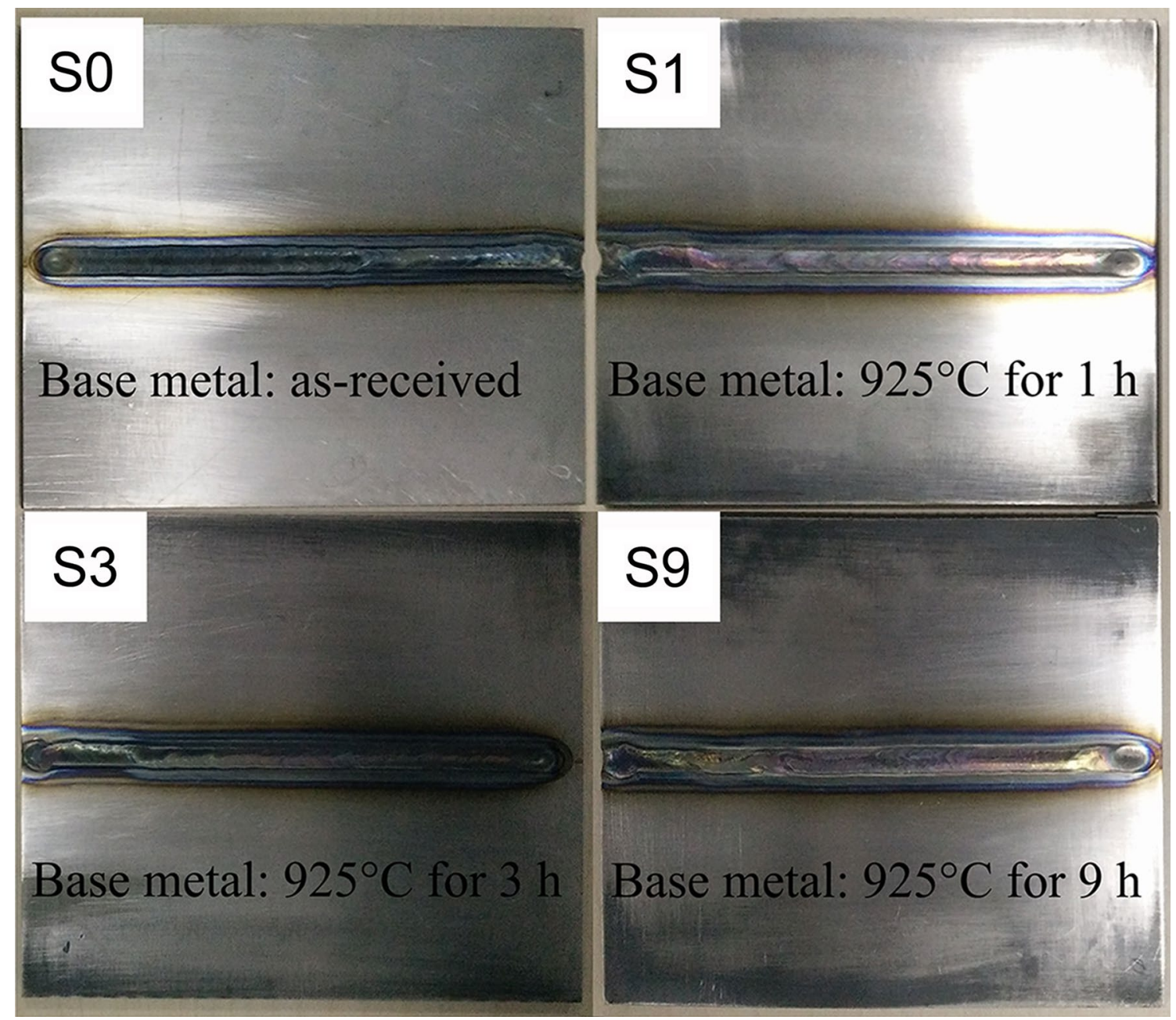

Fig. 1 Four groups of welded superalloys

Table 2 Heat treatment and welding parameters of the samples

\begin{tabular}{lllll}
\hline Designation & Heat treatment parameters & $\begin{array}{l}\text { Welding current, } \\
I(\mathrm{~A})\end{array}$ & $\begin{array}{l}\text { Welding voltage, } \\
U(\mathrm{~V})\end{array}$ & $\begin{array}{l}\text { Welding } \\
\text { speed, } v(\mathrm{~m} / \\
\text { min) }\end{array}$ \\
\hline S0 & As-received & 90 & 13 & 0.2 \\
S1 & $925^{\circ} \mathrm{C}$ for $1 \mathrm{~h}$, air cooled & 90 & 13 & 0.2 \\
S3 & $925^{\circ} \mathrm{C}$ for $3 \mathrm{~h}$, air cooled & 90 & 13 & 0.2 \\
S9 & $925^{\circ} \mathrm{C}$ for $9 \mathrm{~h}$, air cooled & 90 & 13 & 0.2 \\
\hline
\end{tabular}

the intensity of characteristic diffraction peaks. The specific calculation equations are as follows [18]:

$W_{\gamma}+W_{\delta}=1$,

$\frac{W_{\gamma}}{W_{\delta}}=\frac{\rho_{\gamma}}{\rho_{\delta}} \cdot \frac{\frac{1}{n} \cdot \sum_{i}^{n}\left(I_{i}^{\gamma} / R_{i}^{\gamma}\right)}{\frac{1}{m} \cdot \sum_{i}^{m}\left(I_{i}^{\delta} / R_{i}^{\delta}\right)}$, where $W_{\delta}$ and $W_{\gamma}$ are the amount of $\delta$ and $\gamma$ phase in weight percent, respectively; $\rho_{\gamma}$ and $\rho_{\delta}$ are the volume density of $\gamma$ and $\delta$ phase, respectively; $m$ and $n$ are the number of selected diffraction peaks; $I_{i}^{\delta}$ and $I_{i}^{Y}$ are the integrated intensities from $\delta$ and $\gamma$ phases, respectively; $R_{i}$ can be expressed as: 

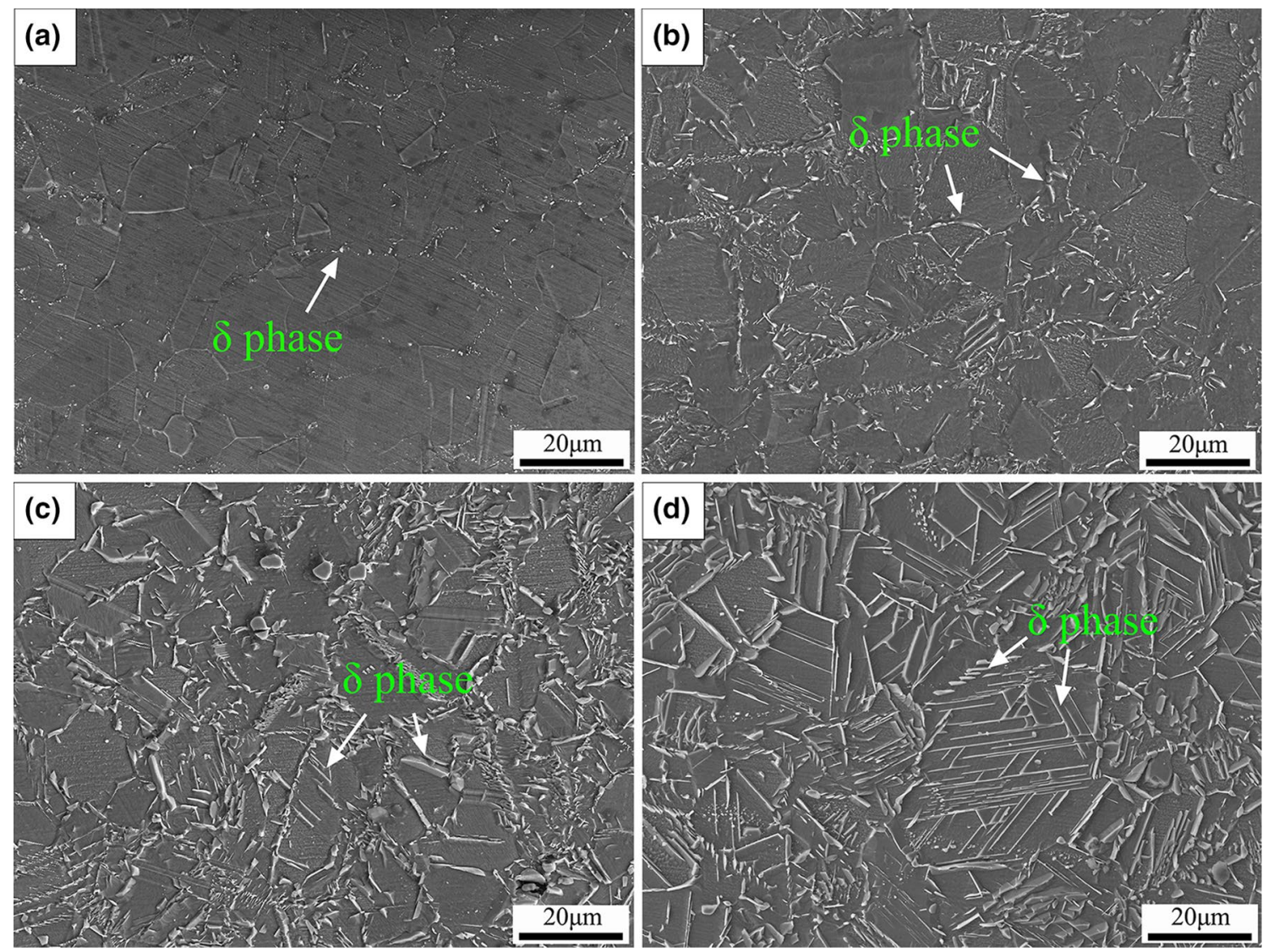

Fig. 2 SEM micrographs of GH4169 in different conditions: a as-received; b $925{ }^{\circ} \mathrm{C}$ for $1 \mathrm{~h}$; $\mathbf{c} 925^{\circ} \mathrm{C}$ for $3 \mathrm{~h}$; d $925{ }^{\circ} \mathrm{C}$ for $9 \mathrm{~h}$
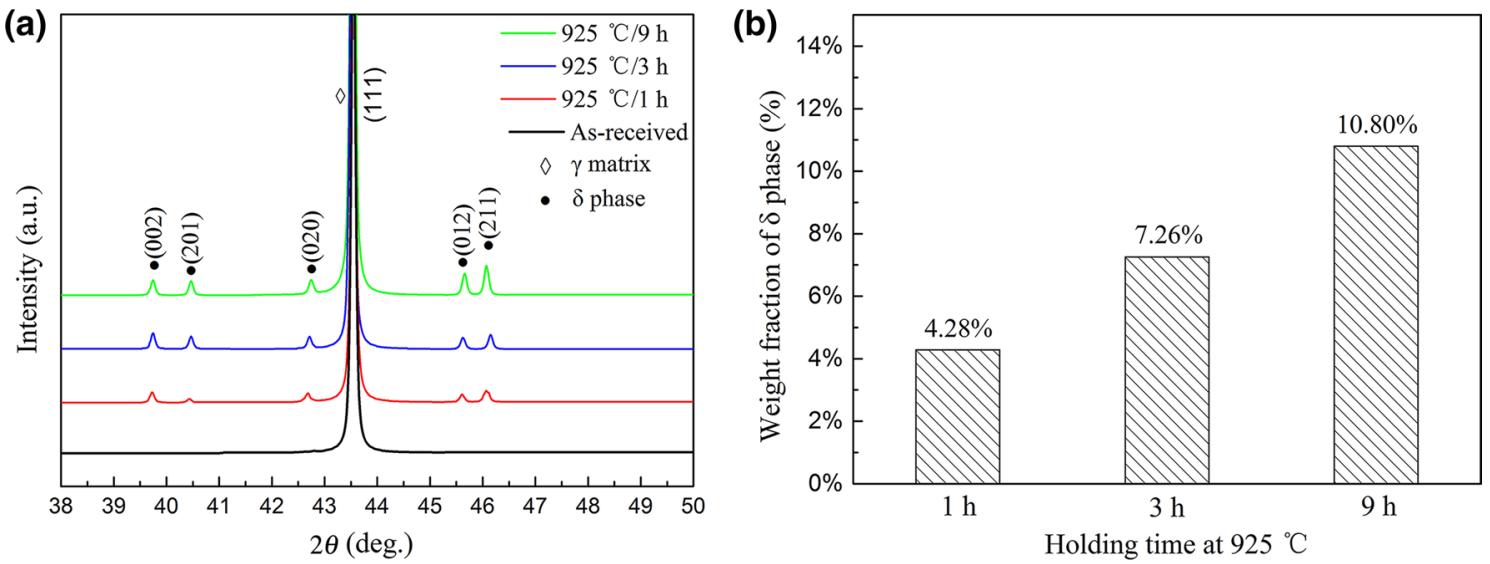

Fig. 3 a X-ray diffraction spectrums of the pre-welding samples with heat treatment at $925^{\circ} \mathrm{C}$ for $1 \mathrm{~h}, 3 \mathrm{~h}$ and $9 \mathrm{~h}$, respectively; b the calculated content of $\delta$ phase in different heat treatment samples

where $v$ is the precise volume of the unit cell, $P_{i}$ is the multiplicity factor of the diffracting plane, $F_{i}$ is the structure factor, $\theta$ is the Lorentz factor, $\varphi$ is the polarization factor, and $\mathrm{e}^{-2 M}$ is the temperature factor. Combining Eqs. (1) and (2) can be expressed as follows:

$$
W_{\delta}=\frac{1}{\frac{\rho_{\gamma}}{\rho_{\delta}} \cdot \frac{\frac{1}{n} \cdot \sum_{i}^{n}\left(I_{i}^{\gamma} / R_{i}^{\gamma}\right)}{\frac{1}{m} \cdot \sum_{i}^{m}\left(I_{i}^{\delta} / R_{i}^{\delta}\right)}} .
$$


The content of $\delta$ phase in weight percentage was calculated by Eq. (4), and the calculation results are shown in Fig. $3 b$.

\subsection{Microstructure of As-Welded HAZ of GH4169 Superalloy}

Figure 4 shows the OM and SEM images of the HAZs in the four groups of as-welded samples (S0, S1, S3 and S9). The
HAZs can be divided into two regions (named as Region1 and Region2, respectively) according to the microstructure characteristics, as shown in Fig. 4a, d, g, j. In Region1 both inter- and intragranular $\delta$ phase is completely dissolved into the $\gamma$ matrix, and some eutectic phase and carbide particles are formed during welding (Fig. $4 \mathrm{~b}, \mathrm{e}, \mathrm{h}, \mathrm{k}$ ). The size of eutectic phase in this region is gradually increased from sample S0 to S9. In addition, it can be found that the eutectic phase tends to distribute along grain boundaries. Figure 5
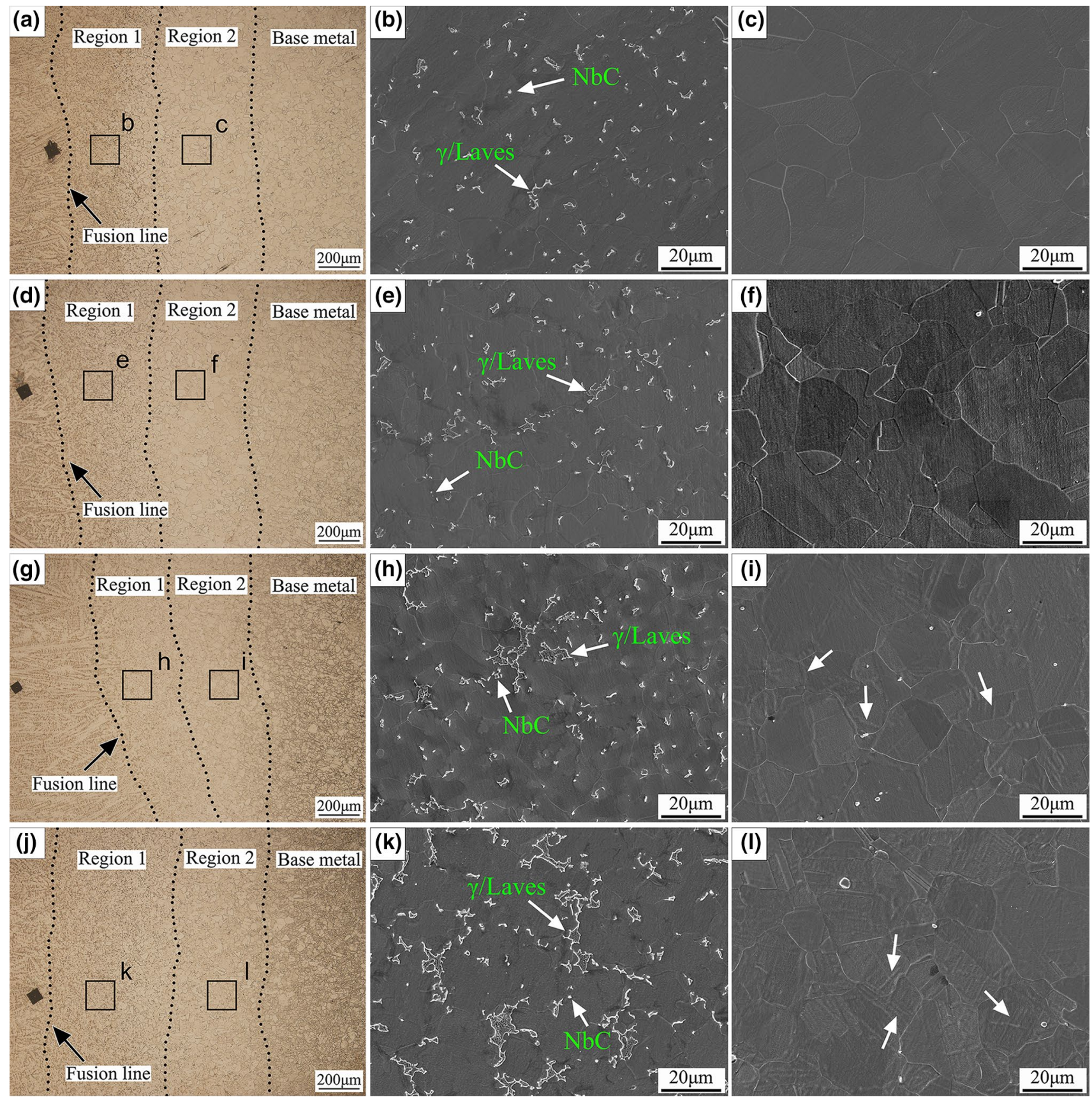

(I)

Fig. 4 OM and SEM images of HAZs in the four welded samples: a, d, $\mathbf{g}, \mathbf{j}$ OM images of HAZs in S0, S1, S3 and S9, respectively; b, e, h, $\mathbf{k}$ SEM images of Region1 in $\mathbf{a}, \mathbf{d}, \mathbf{g}, \mathbf{j}$, respectively; $\mathbf{c}, \mathbf{f}, \mathbf{i}, \mathbf{I}$ SEM images of Region2 in $\mathbf{a}, \mathbf{d}, \mathbf{g}, \mathbf{j}$, respectively 
$a, b$ shows the SEM image and chemical composition of $\delta$ phase in S9, respectively. It is found that the $\delta$ phase is mainly composed of $\mathrm{Ni}$ and $\mathrm{Nb}$ elements. Under the higher magnification in Region1 of S9 (Fig. 5c, e), the eutectic phase exhibits irregular morphology, and the tiny carbide particles have an average size of $\sim 1.0 \mu \mathrm{m}$. The results of EDS in Fig. 5d, f show that the eutectics are rich in Ni, Fe, $\mathrm{Cr}, \mathrm{Nb}$, Mo and $\mathrm{Ti}$ elements and the carbide particles are mainly composed of $\mathrm{C}$ and $\mathrm{Nb}$ elements. It is thus inferred that the eutectics and carbide particles are identified as the $\gamma /$ Laves (Laves-(Ni, $\left.\mathrm{Fe}, \mathrm{Cr})_{2}(\mathrm{Nb}, \mathrm{Mo}, \mathrm{Ti})\right)$ and $\mathrm{NbC}$ particles, respectively [19].

Presented in Fig. 4a, d, g, j, Region2 is farther from the fusion line than Region 1 is. With the increase in distance from fusion line, the peak temperature of weld thermal cycle is gradually decreased. In Region 2 , the intergranular $\delta$ phase is not observed in all samples (Fig. 4c, f, i, 1), while for sample S3 and S9 the outlines of the dissolved intragranular
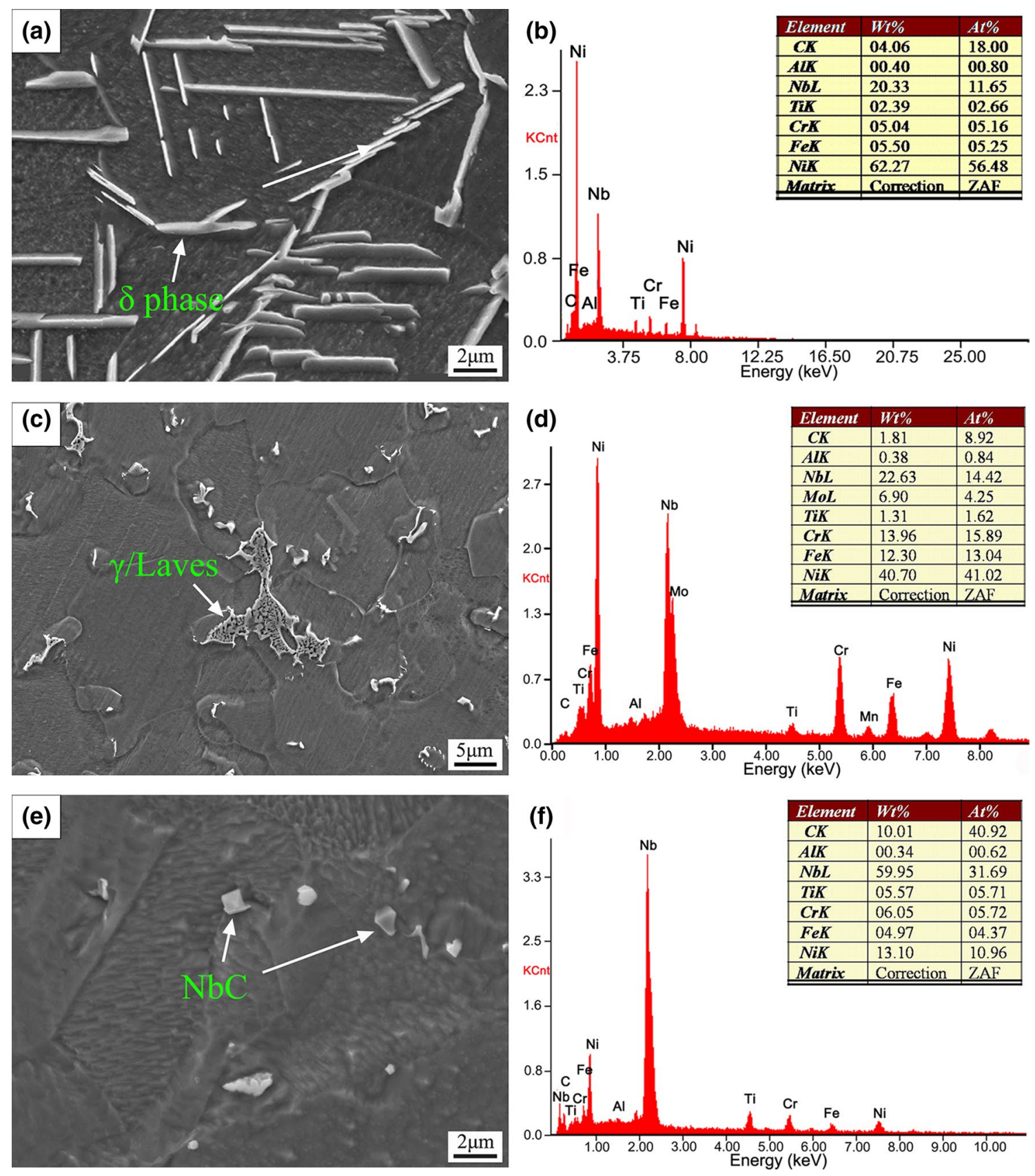

Fig. 5 SEM images and EDS spectrums of $\delta$ phase, Laves phase and $\mathrm{NbC}$ in S9: a SEM image of $\delta$ phase in base metal; b EDS spectrum of $\delta$ phase in a; c SEM image of Laves phase in Region1; d EDS

spectrum of Laves phase in c; e SEM image of $\mathrm{NbC}$ particles in Region 1; f EDS spectrum of $\mathrm{NbC}$ particles in $\mathbf{e}$ 
needle-like $\delta$ phase are still visible in this region (marked with white arrows in Fig. 4i, 1). The absence of $\gamma /$ Laves eutectic constituent in Region2 indicates the temperature range in this region is lower than the precipitation temperature of $\gamma /$ Laves eutectic constituent during welding process.

For the statistic of grain size, 10 magnified $1000 \times$ SEM micrographs in each region were randomly selected. The results of statistic grain size distribution in Region1 and Region2 is shown in Fig. 6. The average grain size of the four pre-welding samples is almost the same $(\sim 15.2 \mu \mathrm{m})$. After welding, the grain size in Region1 is slightly increased compared to the base metal (Fig. 6a). Moreover, from sample S0 to S9, this increasing trend is inhibited. This can be attributed to the increasing $\gamma /$ Laves eutectic constituent and $\mathrm{NbC}$ particles, which play a role in inhibiting the grain growth. Although the peak temperature in Region 2 is lower than that in Region1 during welding process, the average grain size of Region2 is larger than that of Region1 (Fig. 6b). It is also noted that the grain coarsening is inhibited with the increase in $\delta$ phase in base metal. In these two regions of HAZ, the factors affecting the grain growth are different. The main factor affecting the grain growth of Region1 is the $\gamma /$ Laves eutectic constituent. During welding process, the formation of $\gamma /$ Laves eutectic constituent at grain boundaries will restrain the grain growth [20]. In Region1, along the direction away from the fusion line the grain size is gradually increased with the decrease in $\gamma /$ Laves eutectic constituent. However, in Region2, the main factor affecting the grain growth is the content of $\delta$ phase. Along the direction away from the fusion line, the dissolution degree of $\delta$ phase in Region 2 is gradually decreased with the decrease in peak temperature. Therefore, the grain growth is gradually inhibited along this direction.

\subsection{Microstructures of Aging Treatment HAZ}

After welding, the aging treatment is usually required to improve the performance of the welded joint. As the main strengthening phase in GH4169 superalloy, the $\gamma^{\prime \prime}$ particles will precipitate in the $\gamma$ matrix during aging treatment. However, the formation of $\gamma^{\prime \prime}$ phase is closely related to the distribution of $\mathrm{Nb}$ element [21]. The large content of $\delta$ phase in pre-welding material may lead to depletion of $\mathrm{Nb}$ atoms in $\gamma$ matrix, which will have a great impact on the precipitation of $\gamma^{\prime \prime}$ phase.

Figure 7 shows the aging microstructure of HAZ in S0 and S9. Figure 7 a shows that there are some nano-sized $\gamma^{\prime \prime}$ phase particles distributed in Region1 of S0. Mei et al. [22] proved that the nano-sized particles in SEM graphs are $\gamma^{\prime \prime}$ phase in Inconel 718 alloy (similar to GH4169). It can be found that there are more $\gamma^{\prime \prime}$ particles in the vicinity of Laves phase than those in the interior of grains (Fig. 7a). In Region2, however, the content of $\gamma^{\prime \prime}$ particles at the grain boundaries and at the interior of grains is almost the same (Fig. 7b). These results reveal that the Nb element, which is conducive to the formation of $\gamma^{\prime \prime}$ phase [23], is enriched in the vicinity of Laves phase.

Similar to S0, in S9, there are more $\gamma^{\prime \prime}$ particles at the vicinity of $\gamma /$ Laves eutectic constituent than those at interior of grains in Region1 (Fig. 7c). It is found that compared to S0, the content of $\gamma^{\prime \prime}$ phase of S9 is reduced greatly in Region2 (Fig. 7b, d). This is closely related to the difference of initial $\delta$ phase content in base matrix, which can lead to $\mathrm{Nb}$ element enrichment at grain boundaries. It can be inferred that the increase in $\delta$ phase reduced the content of $\mathrm{Nb}$ element in the $\gamma$ matrix, which inhibited the precipitation and growth of $\gamma^{\prime \prime}$ phase.
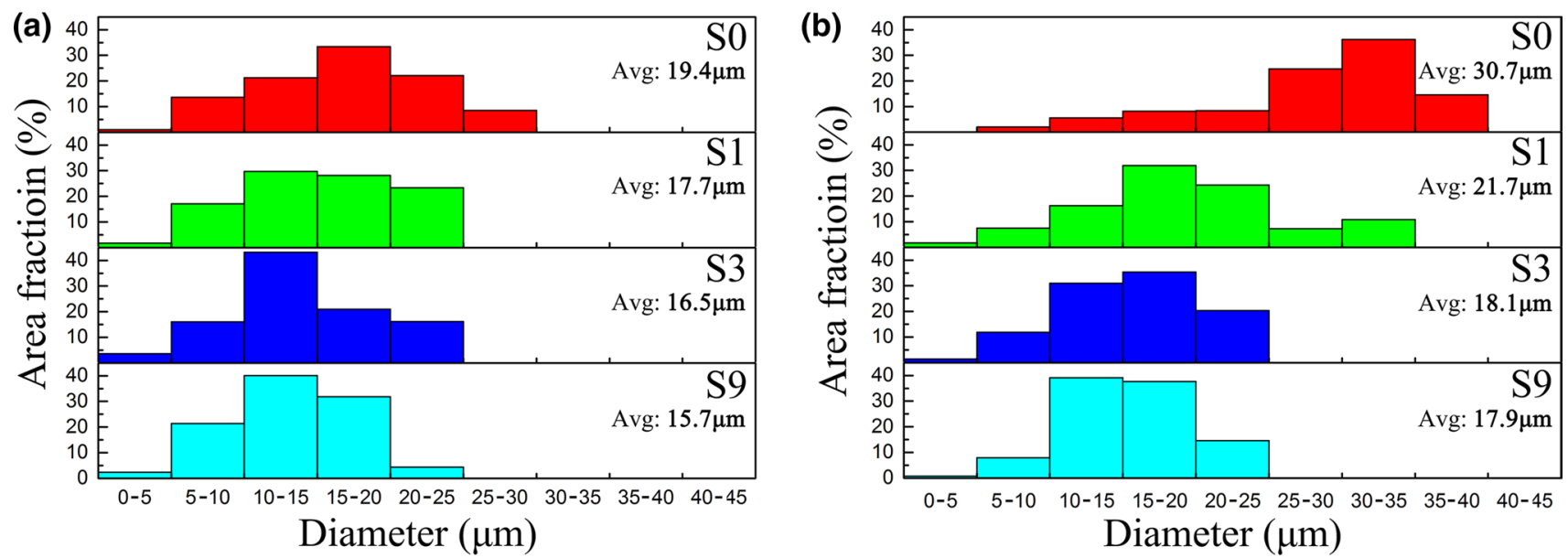

Fig. 6 Grain size distribution and average grain size of Region1 and Region2 in the four welded samples: a grain size distribution of Region1 in the four welded samples; $\mathbf{b}$ grain size distribution of Region 2 in the four welded samples 

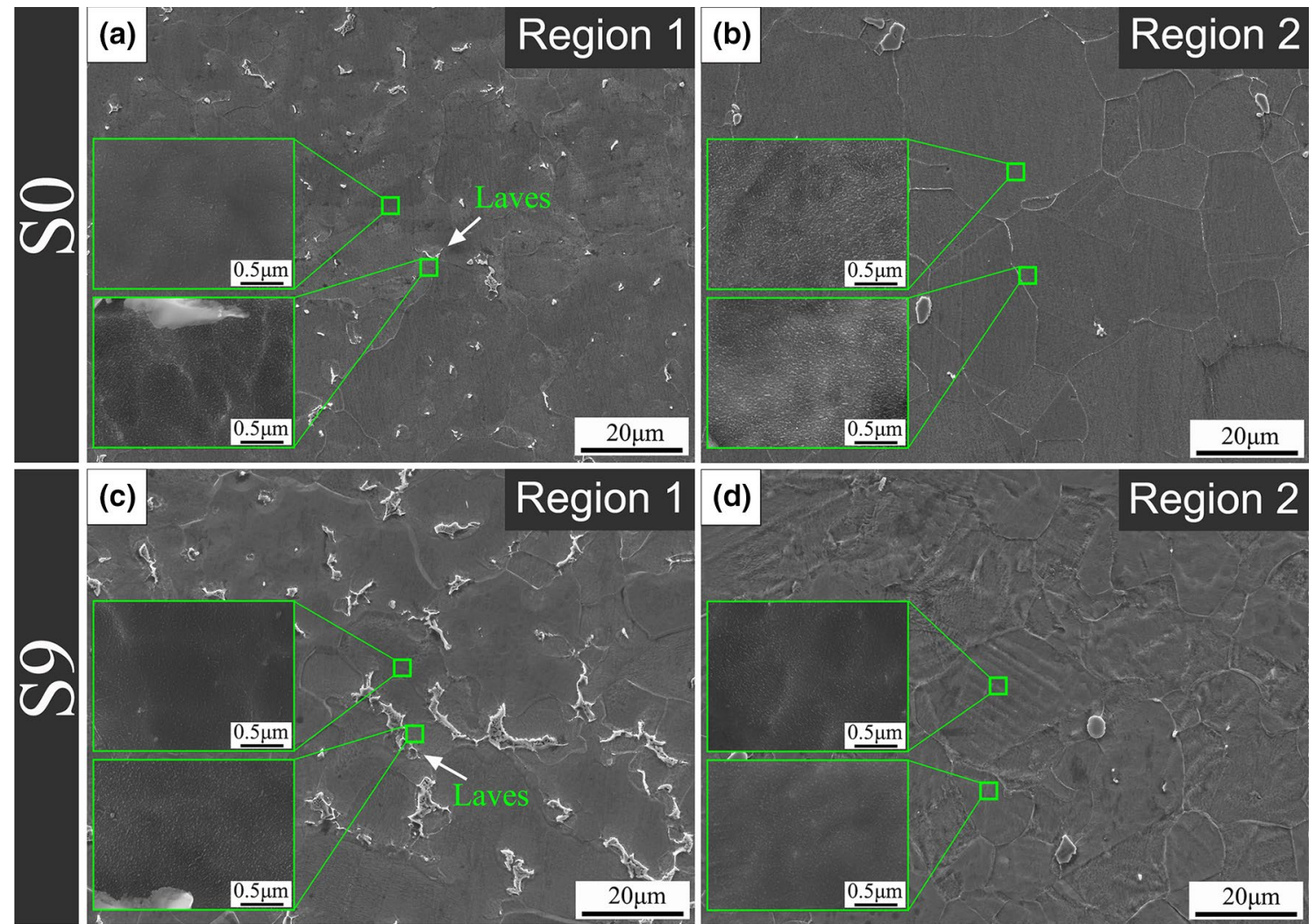

Fig. 7 SEM images of HAZs after aging treatment: a Region1 in S0; b Region2 in S0; $\mathbf{c}$ Region1 in S9; d Region2 in S9

\subsection{Hardness Distribution in HAZ}

Figure 8 shows the Vickers hardness of as-welded and aged superalloys. The hardness profiles of HAZs in both as-welded and aged state show different characteristics in Region1 and Region2. In as-welded state, the hardness profiles exhibit a "V" shape throughout the HAZ (Fig. 8a), that there is an obvious decrease in hardness value in the transition region of Region1 and Region2. In Region1, the hardness profiles of the four groups of welded superalloys are almost the same. However, from the fusion line to base metal, the differences of the four hardness profiles gradually
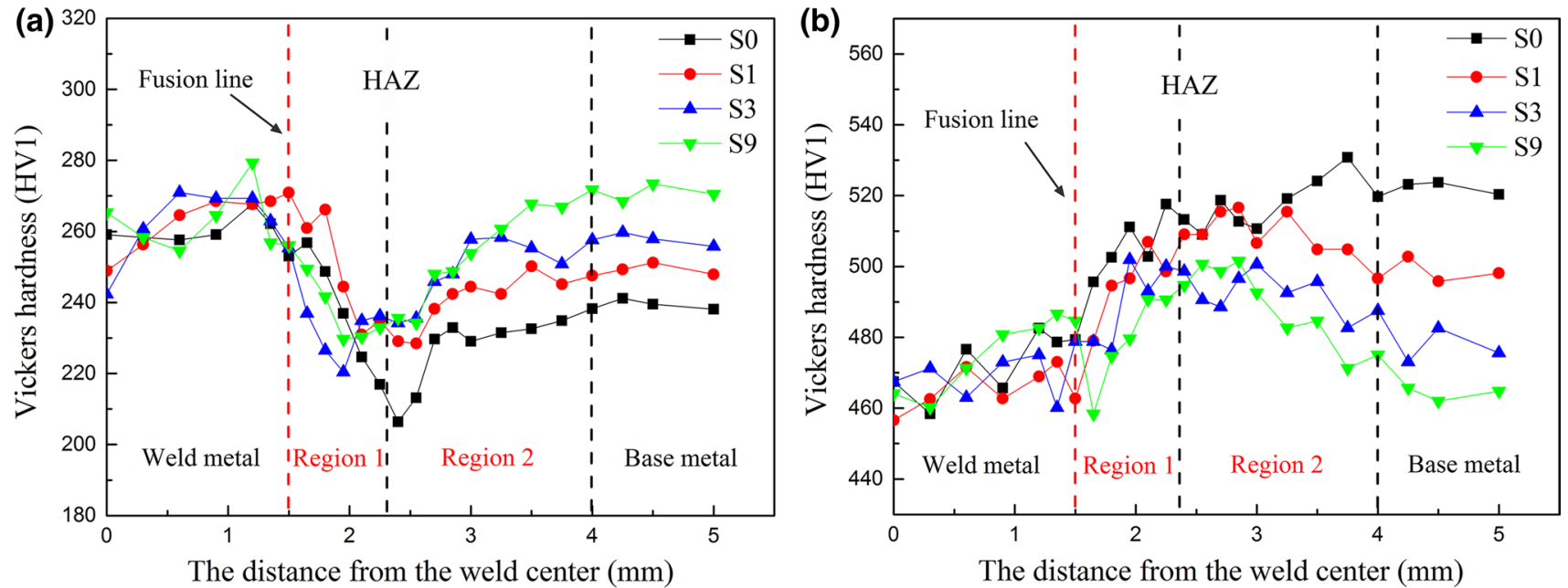

Fig. 8 Vickers hardness profiles of welded joints (S0-S9) in: a as-welded and $\mathbf{b}$ aged condition 
increase. With the increase in $\delta$ phase from S0 to S9, there is a rising trend of the hardness profiles in Region 2 and base metal.

After aging treatment, the hardness values of the four groups of welded superalloys are greatly increased (Fig. 8b). Contrary to the as-welded state, the hardness profiles, except for that of S0, exhibit the " $\Lambda$ " shape, and this characteristic becomes more obvious from sample S1 to S9. Similar to as-welded state, from the transition region of Region 1 and Region2 to base metal, the difference of the four hardness curves gradually increases. Conversely, from sample S0 to S9, the hardness profiles of Region2 and base metal are gradually decreased.

\section{Discussion}

\subsection{Effect of $\delta$ Phase on the Microstructure and Elemental Distribution of HAZ}

Figure 9 shows the elemental distribution maps of the three different regions (base metal, Region1 and Region2) in S9. During welding, the dissolution of $\delta$ phase and the formation of $\gamma /$ Laves eutectic constituent occur in Region1. The formation of $\gamma /$ Laves eutectic constituent in Region 1 indicates that the temperature in this region is higher than $1200{ }^{\circ} \mathrm{C}$ during welding [24]. At such a high temperature, the $\delta$ phase will be dissolved quickly. The precipitation of $\delta$ phase, especially the intergranular $\delta$ phase, results in the local region enriched $\mathrm{Nb}$ and Mo but depleted $\mathrm{Cr}$ and $\mathrm{Fe}$ elements (Fig. 9a). During TIG welding, the enriched $\mathrm{Nb}$ and Mo elements in Region1 can induce the formation of grain boundaries liquation. During the cooling process, the $\gamma /$ Laves eutectic constituent will be formed at grain boundaries, which leads to more significant enrichment of $\mathrm{Nb}$ and Mo elements at grain boundaries (Fig. 9b).

In Region 2 the $\delta$ phase dissolves but the $\gamma /$ Laves eutectic constituent cannot form due to the low peak temperature compared to Region 1 . The dissolving of $\delta$ phase indicates that the peak temperature in Region2 was higher than $980{ }^{\circ} \mathrm{C}$ during welding process [16]. The welding thermal cycle can promote the diffusion of $\mathrm{Nb}$ and Mo elements in this region, leading to the reduced enrichment degree of $\mathrm{Nb}$ and $\mathrm{Mo}$ elements, as shown in Fig. 9c. One point should be noted that the outlines of dissolved $\delta$ phase are mainly located at the interior of grains, but it can hardly be seen at grain boundaries. This implies that the intergranular $\delta$ phase has been fully dissolved. Previous studies $[14,25]$ found that the dissolving process of $\delta$ phase is controlled by the diffusion energy of $\mathrm{Nb}$ atoms. Besides, the grain boundaries can decrease the diffusion energy of $\mathrm{Nb}$ atoms [26]. Therefore, the diffusion energy of intergranular $\delta$ phase is lower than that of intragranular $\delta$ phase, and the intergranular $\delta$ phase is easier to be dissolved than that of intragranular during welding process.

According to the above analysis, the increase in $\delta$ phase in GH4169 superalloy will cause the redistribution of $\mathrm{Nb}$ and Mo elements, especially the intragranular $\delta$ phase. The enriched $\mathrm{Nb}$ and Mo elements at grain boundaries tend to promote the formation of $\gamma /$ Laves eutectic constituent in Region1, which will deteriorate the weldability [27, 28]. But in Region2, the $\delta$ phase can play a beneficial role in inhibiting the grain growth.

Figure 10 schematically shows the redistribution process of $\mathrm{Nb}$ and Mo atoms according to the above discussion. In initial state, the alloy elements are evenly distributed in the $\gamma$ matrix. After a long term of high-temperature service, $\mathrm{Nb}$ and Mo atoms are gradually enriched to the region with high density of lattice defects, especially at the grain boundaries $[23,29]$. Simultaneously the $\delta$ phase precipitates in these regions. And the enrichment of $\mathrm{Nb}$ and Mo atoms gets more obvious with the increase in $\delta$ phase. During welding process, the HAZ is quickly heated to the temperature higher than the dissolution temperature of $\delta$ phase. The enrichment of $\mathrm{Nb}$ and Mo atoms at grain boundaries in Region1 will promote the formation of $\gamma /$ Laves eutectic constituent [30]. Since the enrichment degree of $\mathrm{Nb}$ and Mo atoms at the interior of grains is weaker than that at grain boundaries, there is almost no $\gamma /$ Laves eutectic constituent at the interior of grains. However, due to the lower heating temperature in Region2, there is no eutectic constituent formed. But the enrichment degree of $\mathrm{Nb}$ and $\mathrm{Mo}$ atoms is reduced in Region2 under the welding thermal cycle.

The formation of eutectic constituent in HAZ during welding process has a harmful effect on the weldability, inducing the high sensitivity of HAZ liquation crack [31, 32]. On the other hand, the formation of $\gamma /$ Laves eutectic constituent will also deplete essential alloy elements (such as $\mathrm{Nb}$, Mo and Ti) from the $\gamma$ matrix and reduce tensile strength and ductility $[33,34]$.

\subsection{Effect of $\delta$ Phase on the Hardness Distribution of HAZ}

In as-welded state, the hardness of HAZ is mainly governed by the grain size. Previous analysis suggests that, along the direction away from the fusion line, the grain size is gradually increased in Region 1 but decreased in Region2. Therefore, the relatively large grain size in the transition region of Region1 and Region2 leads to the lowest hardness value, which makes the hardness curves exhibit a "V" shape, as shown in Fig. 8a. In Region1, the grain size distribution of the four welded superalloys is almost the same (Fig. 6a), and thus the four hardness curves in this region is not so different (Fig. 8a). In Region2, from sample S0 to S9, the grain growth is inhibited (Fig. 6b) with the increase in $\delta$ phase in 

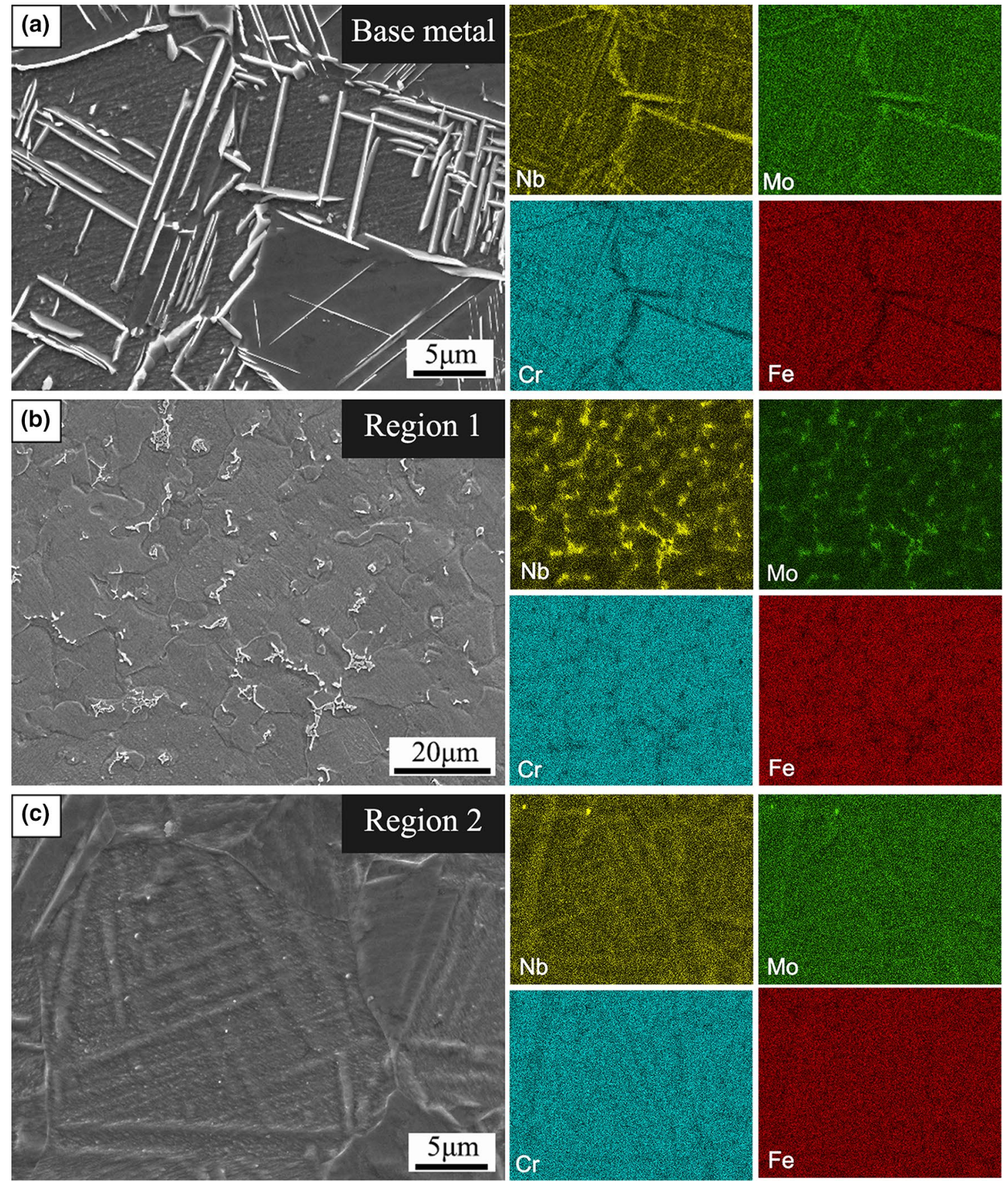

$\mathrm{Fe}$

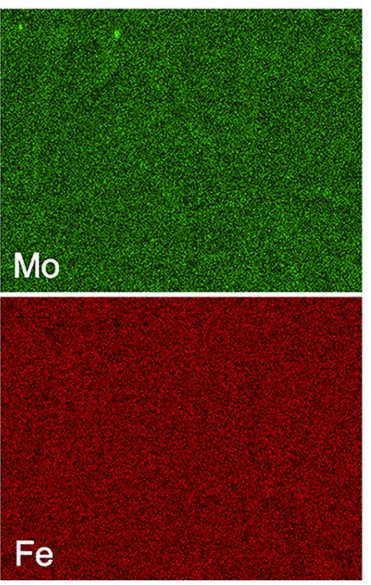

Fig. 9 SEM images and EDS elemental distribution maps of S9 in: a base metal, b Region1 and $\mathbf{c}$ Region2

base metal (Fig. 3b). Therefore, there is an obviously rising trend of the hardness curves in Region2, as shown in Fig. 8a.

In aged state, the $\gamma^{\prime \prime}$ phase plays a key role in hardness, and the hardness distribution can directly reflect the content of $\gamma^{\prime \prime}$ phase in different regions. It is known that the formation of $\gamma^{\prime \prime}$ phase is closely related to the distribution of $\mathrm{Nb}$ element [23]. At the transition region of Region1 and Region2, the $\delta$ phase has completely dissolved and there is no $\gamma /$ Laves eutectic constituent existed. Therefore, the distribution of $\mathrm{Nb}$ element at the transition region of Region1 and Region2 is more uniform than other regions. After aging treatment, large content of $\gamma^{\prime \prime}$ phase precipitates and uniformly distributes at this transition region, which leads to the higher hardness value. This results in the " $\Lambda$ " shape hardness profiles, as shown in Fig. 8b. It is also important to note that the hardness profiles have a downward trend in HAZ formed sample S0 to S9 and this trend in Region2 is more obvious than that of Region1. In Region1, the $\delta$ 


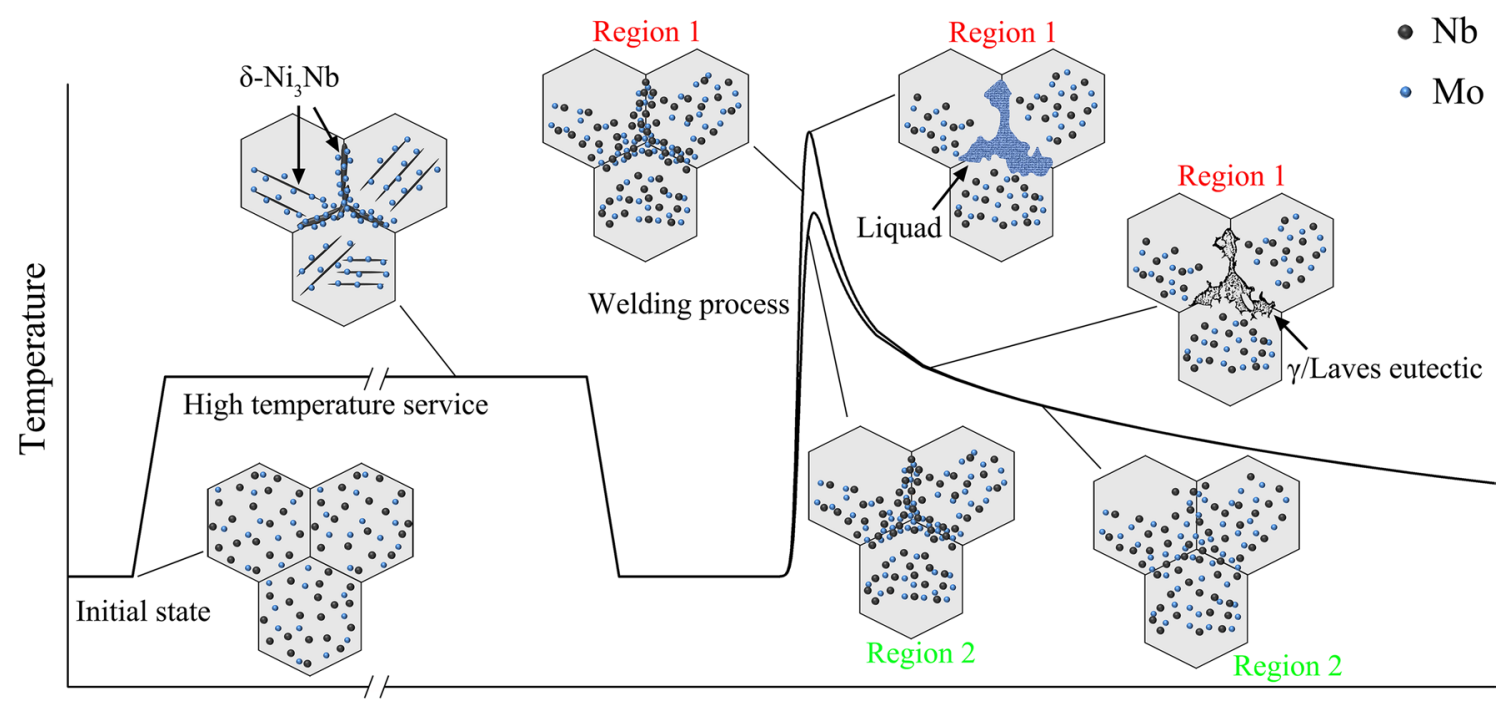

Time

Fig. 10 Schematic of the redistribution of $\mathrm{Nb}$ (colored black) and Mo (colored light blue) atoms and how the $\gamma /$ Laves eutectic constituent formed

phase is completely dissolved in $\gamma$ matrix, but the increase in the $\gamma /$ Laves eutectic constituent can be consumed more $\mathrm{Nb}$ element, which leads to the $\mathrm{Nb}$ element depleted in $\gamma$ matrix. Therefore, after aging treatment, there just a little content of $\gamma^{\prime \prime}$ phase precipitated in $\gamma$ matrix (Fig. 7b, d). Similarly, in Region2, the enrichment degree of $\mathrm{Nb}$ element is increased with the increase in $\delta$ phase from sample S0 to S9. Therefore, from sample S0 to S9, the content of $\gamma^{\prime \prime}$ phase is gradually decreased in Region2, which contributes to the downward trend of hardness profiles.

\section{Conclusions}

This work investigated the microstructure and hardness of HAZ in autogenous TIG-welded GH4169 superalloy with different content of $\delta$ phase. The main conclusions can be summarized as follows:

(1) The $\delta$ phase precipitated in GH4169 superalloy leads to the enrichment of $\mathrm{Nb}$ and Mo elements and the dilution of $\mathrm{Cr}$ and $\mathrm{Fe}$ elements. The enrichment of $\mathrm{Nb}$ and $\mathrm{Mo}$ elements at grain boundaries can promote the formation of $\gamma /$ Laves eutectic constituent in Region1 of HAZ.

(2) The formation of $\gamma /$ Laves eutectic constituent contributes to the more significant enrichment of $\mathrm{Nb}$ and $\mathrm{Mo}$ elements at grain boundaries. This will lead to the $\mathrm{Nb}$ element depleted in $\gamma$ matrix, which can inhibit the precipitation of $\gamma^{\prime \prime}$ phase during aging treatment.

(3) In as-welded state, the hardness profiles exhibit a "V" shape in HAZ, which is governed by the grain size. After aging treatment, however, the $\gamma^{\prime \prime}$ phase plays the key role in hardness and the hardness profiles show a " $\Lambda$ " shape in HAZ.

Acknowledgements This work was financially supported by the National Natural Science Foundation of China (No. 51774213) and the Regional Demonstration Project of Marine Economic Innovation and Development (No. BHSF2017-10).

\section{References}

[1] Editorial board of China Aeronautical Materials Handbook, Wrought Superalloy, 2nd edn. (China Standard Press, Beijing, 2002)

[2] A.B. Mostly, Adv. Mater. Sci. Eng. 3, 123 (2011)

[3] X. Xing, X. Di, B. Wang, J. Alloys Compd. 593, 110 (2014)

[4] L.C.M. Valle, S.B. Gabriel, J. Dille, L.H.D. Almeida, J. Mater. Eng. Perform. 22, 1512 (2013)

[5] J. Saarimäki, M.H. Colliander, J.J. Moverare, Mater. Sci. Eng. A 692, 174 (2017)

[6] J.N. Dupont, J.C. Lippold, S.D. Kiser, Welding Metallurgy and Weldability of Nickel-Base Alloys (Wiley, New Jersey, 2011), pp. 281-284

[7] K. Wang, M.Q. Li, C. Li, Mater. Sci. Technol. 29, 346 (2013)

[8] S.A. Nalawade, M. Sundararaman, J.B. Singh, Mater. Sci. Eng. A 527, 2906 (2010)

[9] J. Andersson, G.P. Sjoberg, L. Viskari, Mater. Sci. Technol. 28, 609 (2012)

[10] J.W. Hooijmans, J.C. Lippold, W. Lin, Superalloys 1997, 721 (1997)

[11] M. Qian, J.C. Lippold, Mater. Sci. Eng. A 340, 225 (2003)

[12] M. Qian, J.C. Lippold, Mater. Sci. Eng. A 456, 147 (2007)

[13] Y. Ning, S. Huang, M.W. Fu, Mater. Charact. 109, 36 (2015)

[14] M. Stockinger, E. Kozeschnik, B. Buchmay, Superalloys 2001, 141 (2001)

[15] C. Silva, M. Song, K. Leonard, Mater. Sci. Eng. A 691, 195 (2017)

[16] F. Liu, Mater. Sci. Forum 748, 760 (2013) 
[17] S. Azadian, L.Y. Wei, R. Warren, Mater. Charact. 53, 7 (2004)

[18] W. Liu, F. Xiao, M. Yao, J. Mater. Sci. Lett. 16, 769 (1997)

[19] X. Ye, X.M. Hua, Y.X. Wu, J. Mater. Process. Technol. 217, 13 (2015)

[20] F. Yan, T. Zhan, S. Liu, J. Mech. Sci. Technol. 31, 5459 (2017)

[21] M. Sundararaman, P. Mukhopadhyay, S. Banerjee, Metall. Trans. A 19, 453 (1988)

[22] Y. Mei, Y. Liu, C. Liu, C. Li, L. Yu, Q. Guo, H. Li, J. Alloys Compd. 649, 949 (2015)

[23] M. Gao, R.P. Wei, Scr. Metall. 32, 987 (1995)

[24] X. Ye, X.M. Hua, M. Wang, J. Mater. Process. Technol. 222, 381 (2015)

[25] X. Di, X. Xing, B. Wang, Acta Metall. 50, 323 (2014)

[26] X.L. Pan, H.Y. Yu, G.F. Tu, Trans. Nonferrous Met. Soc. China 21, 2402 (2011)
[27] G.D.J. Ram, A.V. Reddy, K.P. Rao, Sci. Technol. Weld. Join. 9, $390(2004)$

[28] H. Xiao, S.M. Li, X. Han, Mater. Des. 122, 330 (2017)

[29] W.C. Liu, M. Yao, Z.L. Chen, J. Mater. Sci. 34, 2583 (1999)

[30] K.D. Ramkumar, S. Dev, V. Saxena, Mater. Des. 87, 663 (2015)

[31] K. Saida, Y. Nomoto, H. Okauchi, Sci. Technol. Weld. Join. 17, 1 (2014)

[32] Y. Mei, Y.C. Liu, C.X. Liu, Mater. Des. 89, 964 (2016)

[33] G.M. Reddy, C.V.S. Murthy, K.S. Rao, Int. J. Adv. Manuf. Technol. 43, 671 (2009)

[34] Y. Chen, K. Zhang, J. Huang, Mater. Des. 90, 586 (2016) 